\title{
An analysis of pump-induced artificial ionospheric ion upwelling at EISCAT
}

\author{
M. J. Kosch, ${ }^{1,2}$ Y. Ogawa, ${ }^{3}$ M. T. Rietveld, ${ }^{4}$ S. Nozawa, ${ }^{1}$ and R. Fujii ${ }^{1}$ \\ Received 22 June 2010; revised 7 September 2010; accepted 13 September 2010; published 16 December 2010.
}

[1] Ion outflow from the high-latitude ionosphere is a well-known phenomenon and an important source of plasma for the magnetosphere. It is also well known that pumping the ionosphere with high-power high-frequency radio waves causes electron heating. On a few occasions, this has been accompanied by artificially induced ion upwelling. We analyze such a controlled experiment at EISCAT up to $600 \mathrm{~km}$ altitude. The pump-enhanced electron temperatures reached up to $4000 \mathrm{~K}$ above $350 \mathrm{~km}$, and ion upwelling reached up to $\sim 300 \mathrm{~m} / \mathrm{s}$ above $500 \mathrm{~km}$ altitude. The pump-induced electron pressure gradient can explain the ion velocity below $450 \mathrm{~km}$. Between 450 and $600 \mathrm{~km}$ the electron pressure gradient correlates equally with ion acceleration and ion velocity, which represents the transition altitude to free ion acceleration. The electron gas pressure gradient can explain ion upwelling, at least up to $600 \mathrm{~km}$ altitude. In addition, such active experiments open the possibility to estimating the F layer ion-neutral collision frequency and neutral density with altitude from ground-based observations.

Citation: Kosch, M. J., Y. Ogawa, M. T. Rietveld, S. Nozawa, and R. Fujii (2010), An analysis of pump-induced artificial ionospheric ion upwelling at EISCAT, J. Geophys. Res., 115, A12317, doi:10.1029/2010JA015854.

\section{Introduction}

[2] An important component of magnetospheric plasma is atomic oxygen ions as well as molecular nitrogen and oxygen ions [Chappell, 1988], which flow out of the ionosphere and can affect the dynamics of the magnetosphere [Yau and André, 1997; Moore et al., 1999]. Strong field-aligned bulk ion outflows from the topside ionosphere are observed at high latitudes using incoherent scatter radars in the auroral zone and polar cap [e.g., Jones et al., 1988; Wahlund and Opgenoorth, 1989; Winser et al., 1988] with typical velocities in the range $100-1000 \mathrm{~m} / \mathrm{s}$ below $1000 \mathrm{~km}$ altitude [Ogawa et al., 2010]. However, from radar observations, there are no reports of supersonic ion velocities in the topside ionosphere [Ogawa et al., 2003], although this condition must exist at some altitude in order for the ions to reach the escape velocity.

[3] Wahlund et al. [1992] divided naturally occurring ion outflow into two categories. Type I was associated with a strong perpendicular electric field resulting in enhanced and anisotropic ion temperatures due to frictional heating and low plasma density due to a lack of particle precipitation. Type II was associated with auroral arcs and enhanced electron temperature. Foster et al. [1998] found that $\sim 80 \%$ $(\sim 50 \%)$ of ion outflow events were associated with enhanced

\footnotetext{
${ }^{1}$ Solar-Terrestrial Environment Laboratory, Nagoya University, Nagoya, Japan.

${ }^{2}$ On leave from Physics Department, Lancaster University, Lancaster, UK.

${ }^{3}$ National Institute of Polar Research, Tokyo, Japan.

${ }^{4}$ EISCAT Research Association, Ramfjordmoen, Norway.

Copyright 2010 by the American Geophysical Union. 0148-0227/10/2010JA015854
}

electron (ion) temperatures. To overcome the downward gravitational force, an upward force must be applied. The upward ambipolar electric field can be increased either by enhancing the electron temperature and/or plasma density gradient [e.g., Caton et al., 1996; Ogawa et al., 2000; Su et al., 1999; Wahlund and Opgenoorth, 1989]. Soft particle precipitation $(<500 \mathrm{eV})$ is clearly associated with ion outflow and is particularly effective at achieving the necessary enhanced pressure gradients in the topside ionosphere [Frederick-Frost et al., 2007; Horwitz and Moore, 1997; Seo et al., 1997; Wahlund et al., 1992; Ogawa et al., 2003, 2008]. In addition, Joule heating can also enhance the ion upward pressure to overcome gravity [e.g., McCrea et al., 2000; Winser et al., 1989]. However, electron temperature enhancements appear to be the more effective mechanism for ion outflow from the topside ionosphere [Keating et al., 1990; Seo et al., 1997].

[4] Plasma motion in the ionosphere-thermosphere can be described by the 13-moment transport equation [Schunk, 1975]. In the topside ionosphere various terms can be neglected, e.g., advection for subsonic flow [Ogawa et al., 2006], magnetic mirror force due to ion temperature anisotropy [Ogawa et al., 2000], the height differential of the stress tensor in the vertical direction [Schunk, 1975], the force due to chemical reactions [Ogawa, 2002], as well as heat flux due to ions and neutrals [Conrad and Schunk, 1979]. When simplified further for field-aligned motion, the general momentum equation for topside ionospheric ions is given by

$$
\begin{aligned}
\frac{\partial \vec{V}_{i \|}}{\partial t} & +\nu_{i n}\left(\vec{V}_{\mathrm{i} \|}-\vec{V}_{\mathrm{n} \|}\right) \\
& \approx-\frac{1}{n_{\mathrm{e}} m_{\mathrm{i}}} \frac{\partial\left(n_{\mathrm{e}} k_{\mathrm{B}} T_{\mathrm{i} \|}\right)}{\partial s}-\frac{1}{n_{\mathrm{e}} m_{\mathrm{i}}} \frac{\partial\left(n_{\mathrm{e}} k_{\mathrm{B}} T_{\mathrm{e} \|}\right)}{\partial s}-\vec{g}_{\|},
\end{aligned}
$$


where $\vec{V}_{\mathrm{i} \|}$ and $\vec{V}_{\mathrm{n} \|}$ are the field-aligned ion and neutral velocities, respectively, $t$ is time, $s$ is distance parallel to the field line, $n_{\mathrm{e}}$ is plasma density, $m_{\mathrm{i}}$ is ion mass, $k_{\mathrm{B}}$ is Boltzmann's constant, $T_{\mathrm{i} \|}$ and $T_{\mathrm{e} \|}$ are the field-parallel ion and electron temperatures, respectively, $\vec{g}_{\|}$is the fieldparallel gravitational force, and $\nu_{\text {in }}$ is ion-neutral collision frequency.

[5] The right-hand side of equation (1) contains the electron and ion pressure gradient as well as gravitational acceleration terms. The ion and electron pressure gradients exert an upward force in the topside ionosphere due to the decreasing plasma density with altitude. Ionospheric Joule heating can increase $T_{\mathrm{i}}$ [Cierpka et al., 2000] and soft particle precipitation can increase $T_{\mathrm{e}}$ [e.g., $\mathrm{Su}$ et al., 1999] in the F layer, thereby also creating an upward ion pressure gradient. $T_{\mathrm{e}}$ is an important part of the ambipolar electric field, which is typically about $1 \mu \mathrm{V} / \mathrm{m}$ in the topside ionosphere [Ogawa et al., 2009], and is usually a significant upward force in the topside ionosphere. The downward acceleration is adjusted for the magnetic field inclination $(I)$ such that $\vec{g}_{\|}=g_{\mathrm{s}} \sin (I)$, where $g_{\mathrm{s}}$ is altitude-adjusted gravitational force. The adjustment for angle is small at high latitudes. The left-hand side of equation (1) contains the field-parallel ion acceleration term as well as ion-neutral drag force resulting from collisions between the ions and neutrals, which is important in the topside ionosphere. All the terms in equation (1) can be estimated from EISCAT and model data.

[6] The balance between $\frac{\partial \vec{V}_{\mathrm{i} \|}}{\partial t}$ and $\nu_{\text {in }}\left(\vec{V}_{\mathrm{i} \|}-\vec{V}_{\mathrm{n} \|}\right)$ is largely determined by $\nu_{\text {in }}$, which in the $\mathrm{F}$ region can be expressed as [Schunk and Nagy, 2000]

$$
\nu_{\text {in }}=3.67 \times 10^{-17} n_{\mathrm{n}} \sqrt{T_{\text {in }}}\left(1-0.064 \log _{10} T_{\text {in }}\right)^{2},
$$

where $T_{\text {in }}$ is the average ion-neutral temperature and $n_{\mathrm{n}}$ the neutral density. $T_{\text {in }}$ is fairly constant in the topside ionosphere up to $600 \mathrm{~km} . n_{\mathrm{n}}$ is dominated by atomic oxygen in the $\mathrm{F}$ layer up to $600 \mathrm{~km}$ altitude. However, since $n_{\mathrm{n}}$ decreases rapidly as a function of altitude in the topside ionosphere (approximately 1 order of magnitude from 400 to $550 \mathrm{~km}$ ), it is reasonable to expect $\nu_{\mathrm{in}}\left(\vec{V}_{\mathrm{i} \|}-\vec{V}_{\mathrm{n} \|}\right)$ and $\frac{\partial \vec{V}_{\mathrm{i} \|}}{\partial t}$ will be more important at lower and higher altitudes, respectively.

[7] In order for the ions to occupy the magnetosphere, they have to reach the escape velocity $(\sim 11,170 \mathrm{~m} / \mathrm{s})$. In doing so, ion outflow has to exceed the sound speed $\left(V_{\mathrm{s}}\right)$ in the upper ionosphere, which can be expressed as

$$
V_{\mathrm{s}}=\sqrt{\frac{k_{\mathrm{B}}\left(\gamma T_{\mathrm{i}}+T_{\mathrm{e}}\right)}{m_{\mathrm{i}}}},
$$

where $\gamma$ is the ratio of specific heats ( $5 / 3$ for atomic oxygen). For a typical quiet ionosphere, $T_{\mathrm{i}}=1000 \mathrm{~K}$ and $T_{\mathrm{e}}=1500 \mathrm{~K}$, $V_{\mathrm{s}}=1375 \mathrm{~m} / \mathrm{s}$. As noted above, ion outflow below $1000 \mathrm{~km}$ altitude is normally subsonic.

[8] Natural ion outflow is frequently associated with naturally enhanced ion-acoustic lines (NEIALs) observed by incoherent scatter radars [Forme and Fontaine, 1999; Ogawa et al., 2000] as signals up to several orders of magnitude above the normal background level in the topside ionosphere (typically 600-800 km) [Ogawa et al., 2006]. In addition, NEIALs are frequently associated with enhanced electron temperatures and large fluxes of soft particle precipitation [e.g., Collis et al., 1991; Rietveld et al., 1991; Wahlund et al., 1993]. NEIALs can be caused by very high electrical currents, different ion species drifting relative to each other, or by an electron beam creating Langmuir waves and their parametric decay [Ogawa et al., 2006, and references therein]. However, NEIALs and ion outflow appear to be linked by a common energy source, e.g., soft particle precipitation, rather than one being the mechanism for the other [Buchert et al., 1999]. The soft particle precipitation can increase the electron temperature, which drives the ion outflow via ambipolar diffusion, and at the same time creates the electron beam which drives the NEIALs.

[9] It is well established that pumping the ionosphere with high-power high-frequency radio waves causes plasma heating [e.g., Robinson et al., 1996; Rietveld et al., 2003]. A primary energy exchange mechanism is upper hybrid resonance [Robinson, 1989; Robinson et al., 1996], expressed by $f_{\mathrm{o}}=f_{\mathrm{UH}}=\sqrt{f_{\mathrm{p}}^{2}+f_{\mathrm{GH}}^{2}}$, where $f_{\mathrm{o}}, f_{\mathrm{UH}}, f_{\mathrm{p}}$, and $f_{\mathrm{GH}}$ is the pump, upper hybrid, plasma, and electron gyroharmonic frequency $(\sim 1.35 \mathrm{MHz}$ in the F layer over EISCAT), respectively. Upper hybrid resonance acts perpendicular to the magnetic field line and occurs a few kilometers below the pump wave reflection altitude at high latitudes. The temperature enhancements maximize for pump frequencies away from the electron gyroharmonic frequencies [Robinson et al., 1996], especially when pumping slightly above a gyroharmonic frequency [Gustavsson et al., 2006], and when pumping parallel to the magnetic field line direction [Rietveld et al., 2003] with electron temperatures reaching up to $\sim 4000 \mathrm{~K}$ for nighttime experiments [e.g., Rietveld et al., 2003; Blagoveshchenskaya et al., 2005a]. More modest ion temperature enhancements may also occur up to $\sim 500 \mathrm{~K}$ above background [Rietveld et al., 2003; Blagoveshchenskaya et al., 2005a]. In addition, artificial ion upwelling above $400 \mathrm{~km}$ with upward fieldaligned velocities up to $\sim 300 \mathrm{~m} / \mathrm{s}$ have also been reported by Rietveld et al. [2003] and Blagoveshchenskaya et al. [2005b]. One distinguishing feature of the observations of artificial ion upwelling is that the pump on duration was unusually long, i.e., $4 \mathrm{~min}$, which may explain why the phenomenon has been reported infrequently.

[10] The first observation of pump-induced ion upwelling was reported by Rietveld et al. [2003] at EISCAT (their Figures 1-3) with velocities up to $300 \mathrm{~m} / \mathrm{s}$ at $600 \mathrm{~km}$ altitude. This event was analyzed by Milikh et al. [2010] as part of a study of pump-induced artificial VLF duct formation. They found good agreement between their model calculations and the observed ion upward velocity. In addition, Milikh et al. [2008] provided some satellite evidence at $670 \mathrm{~km}$ altitude for pump-induced ion upwelling at HAARP, although electron temperature and plasma velocity measurements were not available. Here we analyze a new data set from EISCAT and identify the transition altitude between the upward electron pressure gradient force resulting in a constant velocity versus a constant acceleration of the ions. In addition, we show the possibility to use such active experiments to obtain the ionneutral collision frequency and neutral density.

\section{Experiment and Data}

[11] The EISCAT facility in Tromsø, northern Norway $\left(69.58^{\circ} \mathrm{N}, 19.22^{\circ} \mathrm{E}\right)$, includes a $933 \mathrm{MHz} \mathrm{UHF}$ incoherent 


\section{EISCAT UHF RADAR}

\section{SP, uhf, cp1k, 6 October 1998}
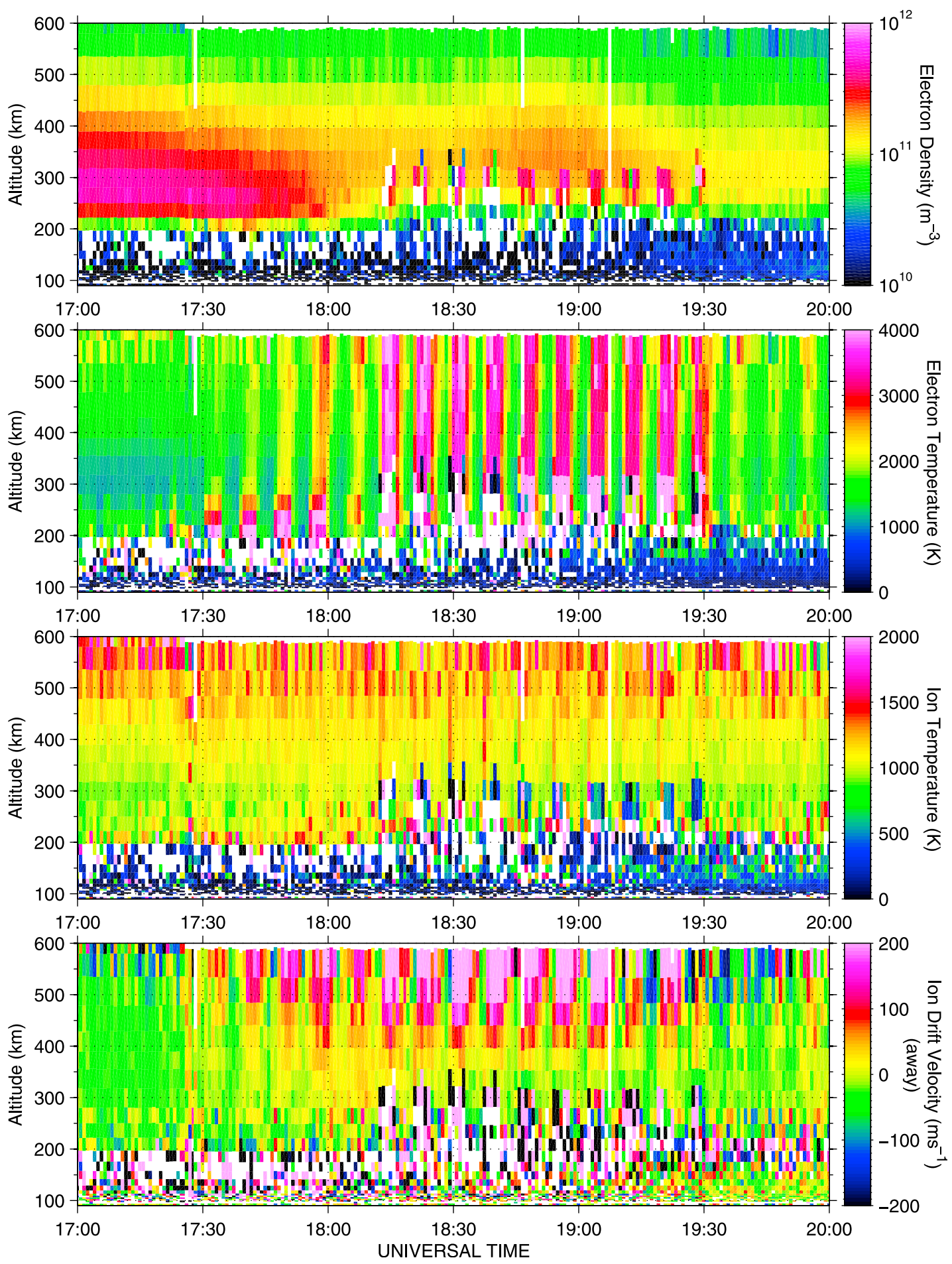

Figure 1. Field-aligned EISCAT UHF radar data for 17-20 UT on 6 October 1998. From top to bottom, the panels show electron density, electron temperature, ion temperature, and ion velocity between 100 and $600 \mathrm{~km}$ altitude. The "noisy data" in each panel below $\sim 350 \mathrm{~km}$ correspond to the pump-induced ion line overshoot phenomenon. 

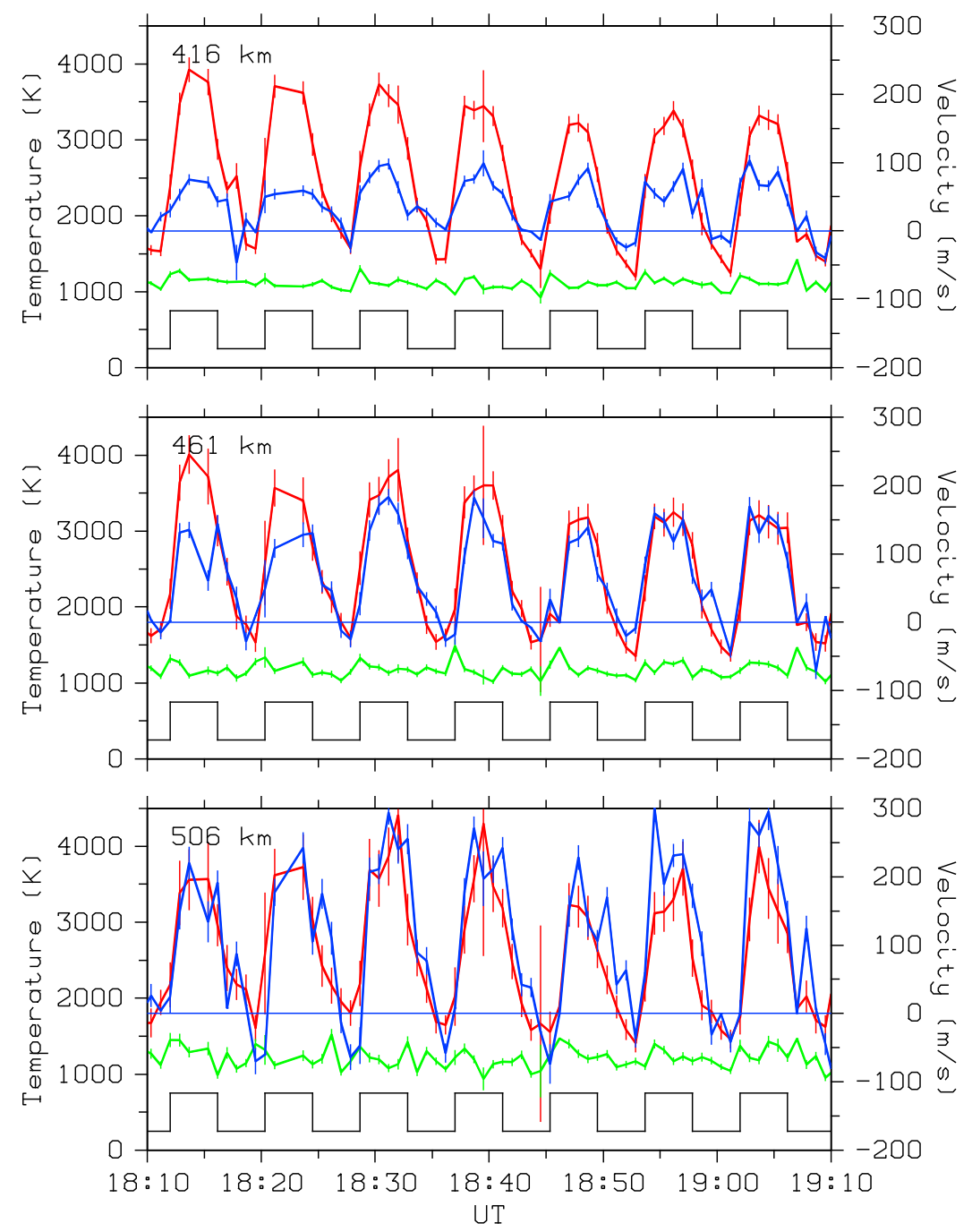

Figure 2. The electron temperature (red), ion temperature (green), and ion velocities (blue) at 416,461 , and $506 \mathrm{~km}$ altitude for 1810 to 1910 UT on 6 October 1998, along with the heater pump cycle. Positive ion velocities are upward.

scatter radar [Rishbeth and van Eyken, 1993] and is colocated with an high-power, high-frequency pump facility for artificial heating of the ionospheric plasma operating between 3.85 and $8 \mathrm{MHz}$ [Rietveld et al., 1993].

[12] On 6 October 1998, the Heater was operated in $\mathrm{O}$ mode using a $250 \mathrm{~s}$ on, $250 \mathrm{~s}$ off cycle with the beam pointing $10^{\circ} \mathrm{S}$ using 11 out of the 12 transmitters. Since the beam is $\sim 14^{\circ}$ wide, the field-aligned direction at $12.8^{\circ} \mathrm{S}$ is also covered. Between 1722 and 1800 UT, the pump frequency was $4.54 \mathrm{MHz}$ with an effective radiated power (ERP) of 96 MW. From 1803 to 1808 UT, the Heater was retuned to $4.04 \mathrm{MHz}$. From 1812 to $2000 \mathrm{UT}$, the Heater was operated as described above, but at $4.04 \mathrm{MHz}$ with 143 MW ERP. The UHF radar was observing field aligned from 90 to $600 \mathrm{~km}$ using the $\mathrm{CP} 1 \mathrm{~K}$ code, which consists of a 16 bit alternating code with a $21 \mu$ s baud length and $3.15 \mathrm{~km}$ range resolution between 89 and $278 \mathrm{~km}$, and a long pulse of $336 \mu \mathrm{s}$ and $22.5 \mathrm{~km}$ range gate separation between 150 and $622.5 \mathrm{~km}$. During this period, it was geomagnetically quiet with $\mathrm{Kp}=1^{+}$. Kp did not exceed $2^{+}$ for more than 3 days prior to the experiment. During the period of interest, IMF Bz remained positive, Tromsø was on the equatorward edge of the dusk convection cell and experienced westward plasma convection of $<300 \mathrm{~m} / \mathrm{s}$.

[13] Figure 1 shows an overview of the data from the EISCAT UHF radar for 17-20 UT on 6 October 1998. From top to bottom, the panels show electron density, electron temperature, ion temperature, and ion velocity between 100 and $600 \mathrm{~km}$ altitude. The data resolution is set to $50 \mathrm{~s}$ in order to get a good signal for the analysis and synchronize with the $500 \mathrm{~s}$ pump cycle. The data below $\sim 200 \mathrm{~km}$ has low signal but does not affect this study. The "noisy data" in each panel below $\sim 350 \mathrm{~km}$ correspond to the pump-induced ion line overshoot phenomenon [Robinson, 1989]. This is the well-known pump-induced Langmuir turbulence effect [Djuth et al., 2004; Rietveld et al., 2000], which is undesirable in this case and makes normal analysis of the incoherent scatter radar spectrum impossible. Unfortunately, the ion line enhancement becomes persistent throughout the heater pulse, as was the case here for 1812 to 1931 UT, when pumping near an electron gyroharmonic [Honary et al., 1999], in this case the third gyroharmonic at 4.04 MHz. 


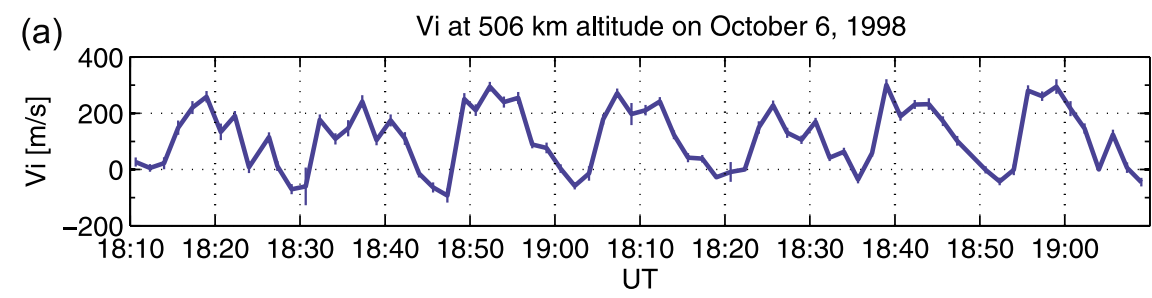

(b) Pressure gradient acceleration (red:ele, green:ion, black:total) at $506 \mathrm{~km}$

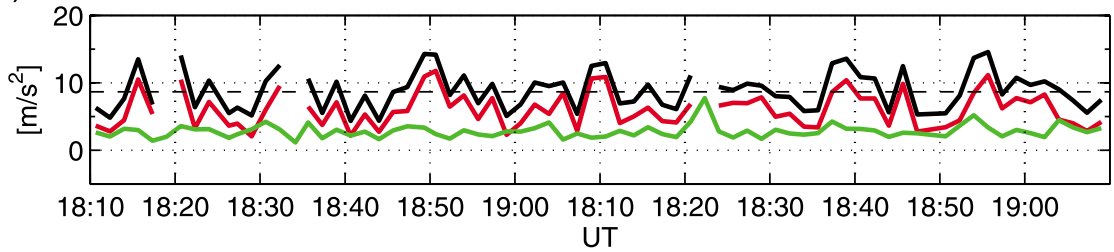

(c) Black: Pressure gradient acceleration - gravity at $506 \mathrm{~km}$, blue: del(Vi)/del(t)

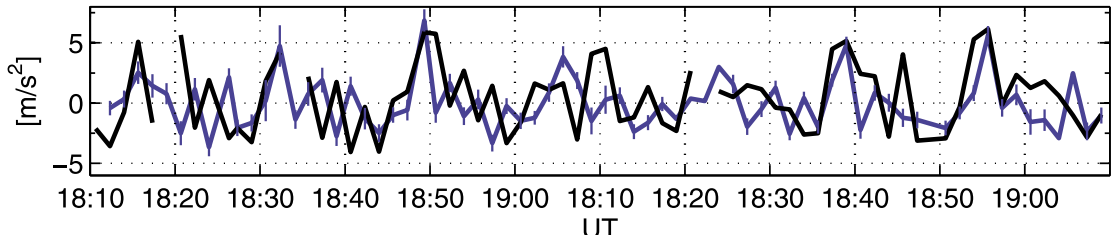

(d) $\quad$ Vi at $416 \mathrm{~km}$ altitude

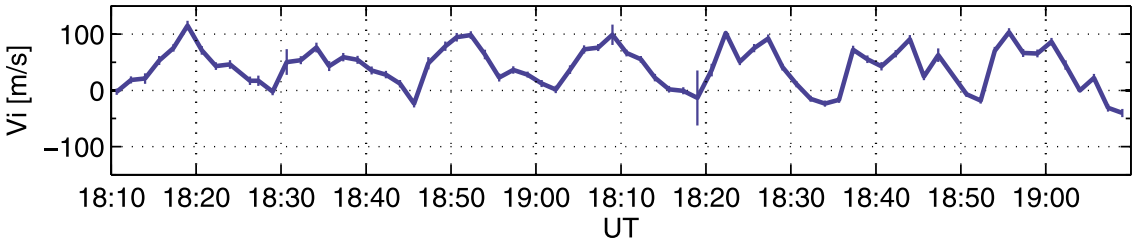

(e) Pressure gradient acceleration (red:ele, green:ion, black:total) at $416 \mathrm{~km}$

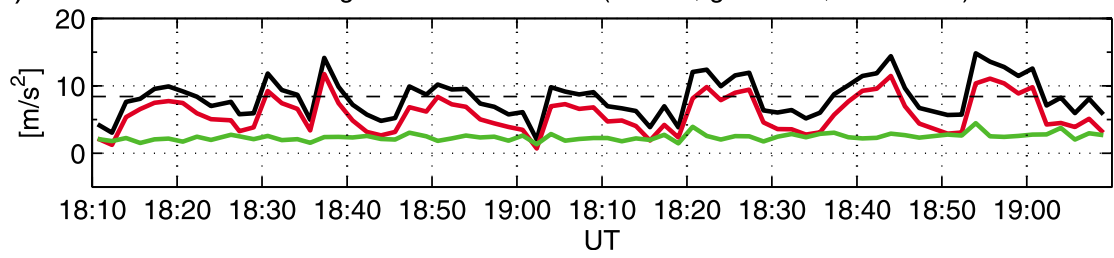

Figure 3. Ion velocity and pressure gradient forces for 1810 to 1910 UT on 6 October 1998. (a) The field-aligned ion velocity at $506 \mathrm{~km}$ altitude. (b) The ion (green), electron (red), and total (black) pressure gradient force at $506 \mathrm{~km}$ altitude. (c) The total pressure gradient minus gravitational acceleration (black) and ion acceleration (blue) at $506 \mathrm{~km}$ altitude. (d) The ion velocity at $461 \mathrm{~km}$ altitude. (e) The ion (green), electron (red), and total (black) pressure gradient force at $461 \mathrm{~km}$ altitude.

[14] Excluding the ion line overshoot effects below $350 \mathrm{~km}$, the electron density data in Figure 1 represents a quiet ionosphere with no structured auroral precipitation. Between 1700 and $1810 \mathrm{UT}$, the critical frequency dropped from $\sim 7.2$ to $\sim 3.7 \mathrm{MHz}$ as the Sun set, which explains the pump frequency change at 1812 UT. Between 1810 and 1925 UT, the critical frequency ranged between $\sim 3.7$ and $\sim 4.1 \mathrm{MHz}$, thereafter dropping below $3.7 \mathrm{MHz}$. At times the pump frequency was above the critical frequency, suggesting plasma resonance would not be possible. However, upper hybrid resonance is possible in an underdense ionosphere for pump frequencies up to $\sim 0.5 \mathrm{MHz}$ above the critical frequency [Kosch et al., 2005]. Pumping near or slightly above the critical frequency is advantageous in the F region because the plasma density gradient is small, giving a long interaction path with the pump wave. In addition, when the plasma density is lower, as is the case toward sunset, then the pumping effect is greater because the same energy is distributed to fewer electrons, assuming other factors such as ERP and pump frequency relative to the electron gyroharmonic remain the same.

[15] The electron temperature data in Figure 1 show large enhancements. Before 1800 UT these remain below $\sim 3000 \mathrm{~K}$ when pumping at $4.54 \mathrm{MHz}$. The pump cycle immediately after 1800 UT corresponds to the $4.04 \mathrm{MHz}$ tune-up. Between 1812 and 1931 UT electron temperature enhancements up to $\sim 4000 \mathrm{~K}$ occur when pumping at $4.04 \mathrm{MHz}$, possibly the greatest ever observed at EISCAT. The HF reflection altitude of $250-300 \mathrm{~km}$, as shown by the ion line enhancements, corresponds to pumping above the third electron gyroharmonic $(\sim 215 \mathrm{~km}$ at $4.04 \mathrm{MHz})$ where plasma temperature enhancements are maximized [Gustavsson et al., 2006]. After 1931 UT, the plasma density reduces to the point 
where upper hybrid resonance is no longer possible and efficient electron heating ceases, leaving only ohmic heating with small temperature enhancements of a few hundred Kelvin. The field-aligned ion velocity data shows clear upwelling above $350 \mathrm{~km}$, sometimes greater than $250 \mathrm{~m} / \mathrm{s}$ above $500 \mathrm{~km}$. There is some evidence of ion downwelling during the pump off periods, presumably due to the same ions returning under the force of gravity. This is especially clear after 1915 UT. There is only weak evidence for the simultaneous downwelling at low altitudes with upwelling at high altitudes, as has been reported by Buchert et al. [2004] for natural ion outflow. The ion line overshoot effect masks any ion flow data below $\sim 350 \mathrm{~km}$ when the pump is on. However, after pump goes off weak ion downwelling can be observed at $\sim 300 \mathrm{~km}$.

[16] We analyze the seven pump cycles between 1810 and 1910 UT in more detail because they show clear pumpinduced ion upwelling for one pump frequency. Figure 2 shows the electron temperature (red), ion temperature (green), and ion velocities (blue) at 416, 461, and $506 \mathrm{~km}$ altitude at $50 \mathrm{~s}$ temporal resolution along with the heater pump cycle for 1810 to 1910 UT. The ion temperature is in the range 1000 $1500 \mathrm{~K}$. The electron temperature is clearly related to the pump cycle with enhancements peaking at $\sim 4000 \mathrm{~K}$ at 416 and $461 \mathrm{~km}$ and $\sim 4500 \mathrm{~K}$ at $506 \mathrm{~km}$ altitude from a background of $\sim 1500 \mathrm{~K}$. The field-aligned ion velocity is also clearly correlated to the electron temperature reaching upward velocities of $\sim 75 \mathrm{~m} / \mathrm{s}$ at $416 \mathrm{~km}, \sim 175 \mathrm{~m} / \mathrm{s}$ at $461 \mathrm{~km}$, and $\sim 300 \mathrm{~m} / \mathrm{s}$ at $506 \mathrm{~km}$. The increase in ion velocity with altitude is consistent with previous observations [e.g., Wahlund et al., 1992]. Toward the end of each pump off period there is clear evidence for ion downwelling up to $-75 \mathrm{~m} / \mathrm{s}$. According to equation (3), the maximum sound speed is $1830 \mathrm{~m} / \mathrm{s}$, so our data are clearly subsonic.

\section{Results and Discussion}

[17] Neutral winds are a potential source of upward pressure on the ions, as expressed in equation (1). Unfortunately, we have no reliable thermospheric neutral wind optical data because of clouds. However, statistical analysis of the winds over Tromsø for $K_{\mathrm{p}}<3$ show that the meridional wind component is close to zero during our period of interest for both solar minimum and maximum [Aruliah et al., 1991]. The zonal wind is of no consequence because the geomagnetic field azimuthal direction is $182^{\circ}$ at Tromsø. Hence, $V_{\mathrm{n} \|}$ in equation (1) is set to zero.

[18] The downwelling observed after 1930 UT in Figure 1, when the electron temperature enhancements were significantly reduced, suggests that it can take a few tens of minutes for the ions to return ballistically downward. As seen in Figure 2, the obvious imbalance between the ions upwelling and downwelling suggests either that the ions were convected away from the magnetic field line connected to the radar, or that some ions managed to reach the escape velocity above $600 \mathrm{~km}$. Since ionospheric plasma convection was weakly westward, presumably many of the ions that experienced upwelling came down westward of Tromsø.

[19] Figure 3 shows the ion velocity and pressure gradient acceleration terms for 1810 to 1910 UT on 6 October 1998 . Figure $3 \mathrm{a}$ shows the field-aligned ion velocity at $506 \mathrm{~km}$ altitude. Figure $3 \mathrm{~b}$ shows the ion (green), electron (red), and total (black) pressure gradient acceleration at $506 \mathrm{~km}$ altitude. Figure $3 \mathrm{c}$ shows the total gradient pressure minus gravitational acceleration (black) and ion acceleration (blue) at $506 \mathrm{~km}$ altitude. Figure $3 \mathrm{~d}$ shows the ion velocity at $416 \mathrm{~km}$ altitude. Figure 3e shows the ion (green), electron (red), and total (black) pressure gradient acceleration at $416 \mathrm{~km}$ altitude. At both altitudes, it is clear that the ion pressure gradient acceleration is small and plays a minor role compared to the dominant electron pressure gradient (Figures $3 \mathrm{~b}$ and $3 \mathrm{e}$ ). The association between the pressure gradient acceleration and ion velocity at $416 \mathrm{~km}$ is clear with a cross-correlation coefficient of 0.73 (Figures $3 \mathrm{~d}$ and $3 \mathrm{e}$ ). This association becomes less obvious at $506 \mathrm{~km}$, where the cross-correlation coefficient is 0.28 (Figures $3 \mathrm{a}$ and $3 \mathrm{~b}$ ). For the pressure gradient minus gravitational acceleration comparison with ion acceleration, the cross-correlation coefficient is 0.35 at $506 \mathrm{~km}$. Hence, both terms on the left hand side of equation (1) are approximately equally correlated with the electron pressure gradient acceleration. However, it is clear that the electron pressure gradient at lower (higher) altitudes relates more clearly to the ion velocity (acceleration). This is to be expected from equation (1) where the relative importance of the ion velocity and acceleration terms on the lefthand side depends on the ion-neutral collision frequency, which in turn depends on the neutral density from equation (2). According to MSISE-90 [Hedin, 1991] the neutral density drops by a factor of 4.8 between 416 and $506 \mathrm{~km}$. Presumably for observations above $600 \mathrm{~km}$ the ion acceleration will become clearly related to the electron pressure gradient. As the altitude increases and the collision frequency decreases, at some point the ion acceleration should be equal to the electron pressure gradient minus gravitational acceleration.

[20] Figure 4 shows scatterplots of ion motion versus the electron pressure gradient acceleration for 1810 to 1910 UT. From top to bottom, the left (right)-hand column shows the ion velocity (acceleration) against the accelerating force for 506, 461, and $416 \mathrm{~km}$ altitude. The dashed lines show the best linear fits to the data. The dotted line in the right-hand panels shows the ideal situation where the ion acceleration equals the accelerating force. At $416 \mathrm{~km}$ altitude, it is clear that the ion velocity is well related to the accelerating force (Figure $4 \mathrm{e}$ ), but the ion acceleration is not (Figure 4f). At this lower altitude, ion-neutral collisions and the high inertia of the neutral thermosphere prevent the ions from accelerating continuously, so only a constant average velocity is achieved. At $461 \mathrm{~km}$ altitude, the relationship between ion velocity and the accelerating force is less clear (Figures 4c and $4 \mathrm{~d}$ ). At $506 \mathrm{~km}$ altitude, the relationship between ion velocity and accelerating force appears to break down (Figure 4a). However, a relationship between ion acceleration and the accelerating force is apparent, although with considerable scatter (Figure 4b). At this higher altitude, the lower neutral density means fewer ion-neutral collisions, so the ions can accelerate under the applied force more freely. It is clear that the ion acceleration starts to approach the accelerating force, as indicated by the dotted lines. It is probably true that a clear relationship between ion acceleration and the electron pressure gradient would become apparent at higher altitudes, but we do not have radar data above $600 \mathrm{~km}$ for this experiment. At some altitude, the ion motion would become essentially unrestricted by collisions 

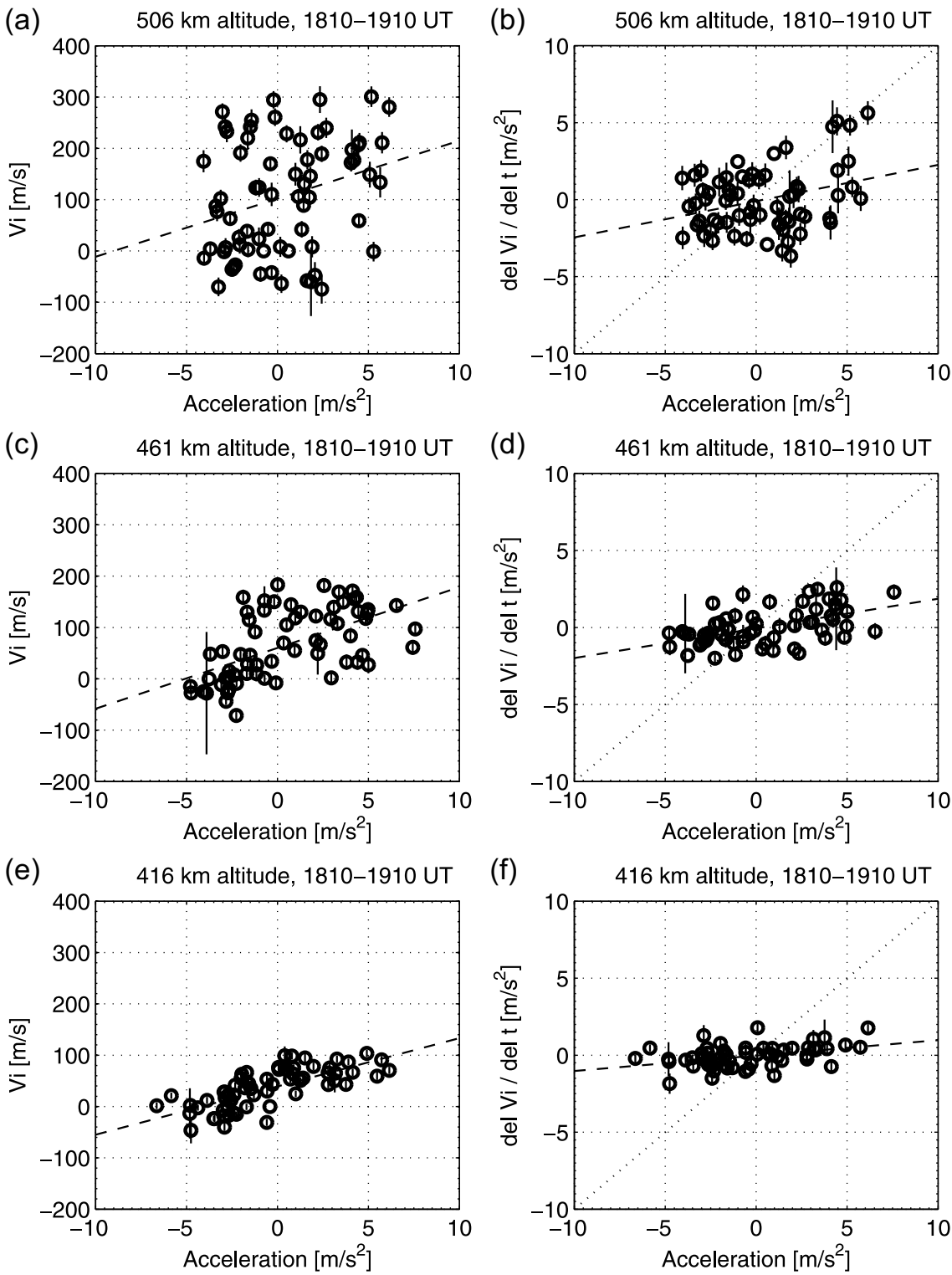

Figure 4. For 1810 to 1910 UT on 6 October 1998, from top to bottom, the left (right)-hand column shows the ion velocity (acceleration) against accelerating force for 506, 461, and $416 \mathrm{~km}$ altitude. The dashed lines represent the best linear fit. The dotted line shows the ideal case where the ion acceleration equals the accelerating force.

and the ion acceleration should be given by the accelerating force.

[21] We estimate the ion-neutral collision frequency $\left(\nu_{\text {in }}\right)$ at $416 \mathrm{~km}$ altitude from the slope of the fit to Figure $4 \mathrm{e}$. Assuming that $\frac{\partial \vec{V}_{\mathrm{i}}}{\partial t}$ and $V_{\mathrm{n}}$ are negligible, equation (1) gives $\nu_{\text {in }}=0.106 \pm 0.034 \mathrm{~s}^{-1}$. Assuming $T_{\mathrm{i}}=T_{\mathrm{n}}=1200 \mathrm{~K}$, equation (2) gives the neutral density $n_{\mathrm{n}}=1.29 \times 10^{14} \mathrm{~m}^{-3}$. The MSISE-90 model predicts a neutral density of $7.11 \times$ $10^{13} \mathrm{~m}^{-3}$, which is a factor of $1.8 \times$ lower compared to our estimate. Although the uncertainty increases, at $461 \mathrm{~km} \nu_{\text {in }}=$ $0.084 \pm 0.036 \mathrm{~s}^{-1}$ and $n_{\mathrm{n}}=1.03 \times 10^{14} \mathrm{~m}^{-3}$. MSISE-90 predicts $n_{\mathrm{n}}=3.36 \times 10^{13} \mathrm{~m}^{-3}$, a discrepancy of $3.3 \times$. In both cases, our neutral density estimate is substantially less than MSISE-90, the discrepancy being significantly greater than the root mean square error of the fit. Although our data set is too small to be definitive, the outcome suggests that the neutral density obtained from the MSIS model at high latitudes may need significant correction. A number of groundbased and satellite observations have led to substantial corrections of the MSISE-90 model (up to 100\%) [e.g., Bush and Chakrabarti, 1995; Upadhayaya and Singh, 2002; Pant and Sridharan, 1998]. Artificial ion upwelling provides a new tool for estimating $\nu_{\text {in }}$ and $n_{\mathrm{n}}$ in the upper atmosphere as a function of altitude, both of which are not easily obtained by remote measurements.

[22] Due the association of NEIALs with natural ion outflow, we have checked the UHF radar spectral data for signs of artificially enhanced ion acoustic lines above $300 \mathrm{~km}$. None were found. These signatures are not to be confused with the pump-induced ion line enhancement observed below $300 \mathrm{~km}$ (see Figure 1). This provides evidence that NEIALs and naturally enhanced electron temperatures occur together 
as the result of a common energy source, such as soft particle precipitation, and that NEIALs are not the result of enhanced electron temperature alone.

[23] Wahlund et al. [1992] observed natural ion outflow at EISCAT up to $1500 \mathrm{~km}$ altitude. They noted that strong natural ion outflow occurred almost half the time above $800 \mathrm{~km}$ and that ion velocity tended to increase at higher altitudes. Blagoveshchenskaya et al. [2005b] also noted that the pump-induced ion velocities increased with altitude, at least up to their maximum of $500 \mathrm{~km}$. Our results confirm this trend. Hence, obtaining data above $600 \mathrm{~km}$ altitude during controlled experiments is highly desirable because the process of ion acceleration as a function of electron pressure gradient force can be investigated in more detail. Since the ion upwelling is clearly subsonic up to $600 \mathrm{~km}$ altitude, it may also be possible to observe pump-induced ion acceleration to supersonic velocities $(>1000 \mathrm{~m} / \mathrm{s})$ beyond $600 \mathrm{~km}$, which is a necessary hurdle for the ions to reach the escape velocity $(\sim 11,170 \mathrm{~m} / \mathrm{s})$ in order to populate the magnetosphere.

[24] Having longer pump cycles, in particular longer pump-off periods, is also desirable in order to investigate the subsequent ion downwelling more thoroughly. If the ions do not reach the escape velocity, then they must either convect out of the radar beam or move back down the magnetic field ballistically. To avoid convection removing all the ions from the magnetic field line connected to the radar, very quiet geomagnetic conditions are needed. To investigate ion downwelling during the pump pulse itself, the pump frequency should be set to avoid multiples of the electron gyrofrequency in the F region, as this will eliminate the persistent ion line overshoot phenomenon (except for the first few seconds after pump on).

\section{Conclusions}

[25] We have analyzed pump-induced artificial ion upwelling at EISCAT in some detail. The pump-enhanced electron temperatures reached $\sim 4000 \mathrm{~K}$ above $350 \mathrm{~km}$, and ion upwelling reached $\sim 300 \mathrm{~m} / \mathrm{s}$ above $500 \mathrm{~km}$ altitude. The pump-induced electron pressure gradient can explain the ion velocity below $450 \mathrm{~km}$, confirmed by a reasonable deduction of the ion-neutral collision frequency. Above $450 \mathrm{~km}$ the electron pressure gradient correlates equally with ion acceleration and ion velocity, which is expected for a decreasing neutral density with increasing altitude. Presumably, above $600 \mathrm{~km}$ altitude ion acceleration will be determined by the electron pressure gradient, but this awaits confirmation by obtaining suitable high-altitude radar data. However, below $600 \mathrm{~km}$, the electron gas pressure gradient can explain the observed natural ion outflow. In addition, we have demonstrated that this active experiment provides a new method to obtain the ionospheric $\mathrm{F}$ layer ion-neutral collision and hence neutral density as a function of altitude.

[26] Acknowledgments. EISCAT is an international association supported by research organizations in China (CRIRP), Finland (SA), Germany (DFG), Japan (NIPR and STEL), Norway (NFR), Sweden (VR), and the United Kingdom (STFC). M.J.K. acknowledges funding support for his Visiting Professorship at the Solar-Terrestrial Environment Laboratory of Nagoya University. The data used come from an UK EISCAT experiment for a different purpose by J. A. Davies, then at University of Leicester. Useful discussion on the enhanced ion acoustic lines and enhanced electron temperature with S. C. Buchert is acknowledged.

[27] Robert Lysak thanks the reviewers for their assistance in evaluating this paper.

\section{References}

Aruliah, A. L., et al. (1991), The combined effect of solar and geomagnetic activity on high-latitude thermospheric winds: Part I. Observations, J. Atmos. Terr. Phys., 53, 467-481.

Blagoveshchenskaya, N. F., et al. (2005a), Phenomena in the ionospheremagnetosphere system induced by injection of powerful HF radio waves into nightside auroral ionosphere, Ann. Geophys., 23, 87-100.

Blagoveshchenskaya, N. F., et al. (2005b), Heater-induced phenomena in a coupled ionosphere-magnetosphere system, Adv. Space Res., 38 2495-2502.

Buchert, S. C., et al. (1999), Naturally enhanced ion acoustic lines seen with the EISCAT Svalbard radar, Adv. Space Res., 23, 1699-1704.

Buchert, S. C., et al. (2004), Observations of diverging field-aligned ion flow with the ESR, Ann. Geophys., 22, 889-899.

Bush, B. C., and S. Chakrabarti (1995), Analysis of Lyman $\alpha$ and He I 584-A airglow measurements using a spherical radiative transfer model, J. Geophys. Res., 100(A10), 19,609-19,625, doi:10.1029/95JA01210.

Caton, R., et al. (1996), Modeling of F region ionospheric upflows observed by EISCAT, Geophys. Res. Lett., 23(12), 1537-1540, doi:10.1029/96GL01255.

Chappell, C. R. (1988), The terrestrial plasma source: A new perspective in solar-terrestrial process from Dynamic explorer, Rev. Geophys., 26, 229-248.

Cierpka, K., et al. (2000), Ion-Neutral Coupling in the high-latitude F layer from incoherent scatter and Fabry-Perot interferometer measurements, Ann. Geophys., 18, 1145-1153.

Collis, P. N., et al. (1991), EISCAT radar observation of enhanced incoherent scatter spectra and their relation to red aurora and field-aligned currents, Geophys. Res. Lett., 18(6), 1031-1034, doi:10.1029/91GL00848.

Conrad, J. R., and R. W. Schunk (1979), Diffusion and heat flow equations with allowance for large temperature differences between interacting species, J. Geophys. Res., 84(A3), 811-822, doi:10.1029/ JA084iA03p00811.

Djuth, F. T., et al. (2004), The first one hundred milliseconds of HF modification at Tromsø, Norway, J. Geophys. Res., 109, A11307, doi:10.1029/ 2003JA010236.

Forme, F. R. E., and D. Fontaine (1999), Enhanced ion acoustic fluctuations and ion outflows, Ann. Geophys., 17, 182-189.

Foster, C., et al. (1998), A statistical study of diurnal, seasonal and solar cycle variations of $\mathrm{F}$ region and topside auroral upflows observed by EISCAT between 1984 and 1996, Ann. Geophys., 16, 1144-1158.

Frederick-Frost, K. M., et al. (2007), SERSIO: Svalbard EISCAT rocket study of ion outflows, J. Geophys. Res., 112, A08307, doi:10.1029/ 2006JA011942.

Gustavsson, B., et al. (2006), Electron gyroharmonic effects in ionization and electron acceleration during HF pumping in the ionosphere, Phys. Rev. Lett., 97, 195002, doi:10.1103/PhysRevLett.97.195002.

Hedin, A. E. (1991), Extension of the MSIS thermospheric model into the middle and lower atmosphere, J. Geophys. Res., 96(A2), 1159-1172, doi:10.1029/90JA02125.

Honary, F., et al. (1999), First direct observations of the reduced striations at pump frequencies close to the electron gyroharmonics, Ann. Geophys., $17,1235-1238$.

Horwitz, J. L., and T. E. Moore (1997), Four contemporary issues concerning ionospheric plasma flow to the magnetosphere, Space Sci. Rev., 80, 49-76.

Jones, G. O. L., et al. (1988), large plasma velocities along the magnetic field line in the auroral zone, Nature, 336, 231-232.

Keating, J. G., et al. (1990), A statistical study of large field-aligned flows of thermal ions at high-latitudes, Planet. Space Sci., 38, 1187-1201.

Kosch, M. J., et al. (2005), Artificial optical emissions at HAARP for pump frequencies near the third and second gyroharmonic, Ann. Geophys., 23, 1585-1592.

McCrea, I. W., et al. (2000), ESR and EISCAT observations of the response of the cusp and cleft to IMF orientation changes, Ann. Geophys., 18, 1009-1026.

Milikh, G. M., et al. (2008), Formation of artificial ionospheric ducts, Geophys. Res. Lett., 35, L17104, doi:10.1029/2008GL034630.

Milikh, G. M., et al. (2010), Model for artificial ionospheric duct formation due to HF heating, Geophys. Res. Lett., 37, L07803, doi:10.1029/ 2010GL042684.

Moore, T. E., et al. (1999), Source processes in the high-latitude ionosphere, Space Sci. Rev., 88, 7-84. 
Pant, T. K., and R. Sridharan (1998), A case-study of the low-latitude thermosphere during geomagnetic storms and its new representation by improved MSIS model, Ann. Geophys., 16, 1513-1518.

Ogawa, Y. (2002), Generation mechanisms of ion upflow in the polar topside ionosphere, Ph.D. thesis, Nagoya Univ., Japan.

Ogawa, Y., et al. (2000), Simultaneous EISCAT Svalbard and VHF radar observations of ion upflows at different aspect angles, Geophys. Res. Lett., 27(1), 81-84, doi:10.1029/1999GL010665.

Ogawa, Y., et al. (2003), Simultaneous EISCAT Svalbard radar and DMSP observations of the ion upflow in the dayside polar ionosphere, $J$ Geophys. Res., 108(A3), 1101, doi:10.1029/2002JA009590.

Ogawa, Y., et al. (2006), Naturally enhanced ion-acoustic lines at high altitudes, Ann Geophys., 24, 3351-3364.

Ogawa, Y., et al. (2008), Coordinated EISCAT Svalbard radar and Reimei satellite observations of ion upflows and suprathermal ions, J. Geophys. Res., 113, A05306, doi:10.1029/2007JA012791.

Ogawa, Y., et al. (2009), On the source of the polar wind in the polar topside ionosphere: First results from the EISCAT Svalbard radar, Geophys. Res. Lett., 36, L24103, doi:10.1029/2009GL041501.

Ogawa, Y., et al. (2010), Solar activity dependence of ion upflow in the polar ionosphere observed with the EISCAT Tromsø UHF radar, $J$ Geophys. Res., 115, A07310, doi:10.1029/2009JA014766.

Rietveld, M. T., P. Collis, and J.-P. St.-Maurice (1991), Naturally enhanced ion acoustic waves in the auroral ionosphere observed with the EISCAT 933-MHz radar, J. Geophys. Res., 96(A11), 19,29119,305, doi:10.1029/91JA01188.

Rietveld, M. T., et al. (1993), Introduction to Ionospheric heating at Tromso I-Experimental overview, J. Atmos. Terr. Phys., 55, 577-599.

Rietveld, M. T., et al. (2000), Measurements of HF-enhanced plasma and ion lines at EISCAT with high altitude resolution, J. Geophys. Res., 105(A4), 7429-7439, doi:10.1029/1999JA900476.

Rietveld, M. T., et al. (2003), Ionospheric electron heating, optical emis sions and striations induced by powerful HF radio waves at high latitudes: Aspect angle dependence, J. Geophys. Res., 108(A4), 1141, doi:10.1029/2002JA009543.

Rishbeth, H., and A. P. van Eyken (1993), EISCAT: Early history and the first ten years of operation, J. Atmos. Terr. Phys., 55, 525-542.

Robinson, T. R. (1989), The heating of the high latitude ionosphere by high power radio waves, Phys. Reports, 179, 79-209.

Robinson, T. R., et al. (1996), First EISCAT observations of the modification of $\mathrm{F}$ region electron temperatures during $\mathrm{RF}$ heating at harmonics of the electron gyro frequency, J. Atmos. Terr. Phys., 58, 385-395.
Schunk, R. W. (1975), Transport equations for aeronomy, Planet. Space Sci., 23, 437-485.

Schunk, R. W., and A. F. Nagy (2000), Ionospheres: Physics, Plasma Physics, and Chemistry, Cambridge Univ. Press, New York.

Seo, Y., et al. (1997), Statistical relationships between high-latitude ionospheric F region/topside upflows and their drivers: DE 2 observations, J. Geophys. Res., 102(A4), 7493-7500, doi:10.1029/97JA00151.

Su, Y.-J., et al. (1999), Systematic modeling of soft-electron precipitation effects on high-latitude $\mathrm{F}$ region and topside ionospheric upflows, $J$. Geophys. Res., 104(A1), 153-163, doi:10.1029/1998JA900068.

Upadhayaya, A. K., and V. Singh (2002), Correction to daytime mesospheric atomic oxygen density in MSIS-90 obtained from WINDII measurements of $\mathrm{O}(1 \mathrm{~S})$ dayglow emissions, Indian J. Rad. Space Phys., 31 $28-33$

Wahlund, J.-E., and H. J. Opgenoorth (1989), EISCAT observations of strong ion outflows from the $\mathrm{F}$ region ionosphere during auroral activity: Preliminary results, Geophys. Res. Lett., 16(7), 727-730, doi:10.1029/ GL016i007p00727.

Wahlund, J.-E., et al. (1992), EISCAT observations of strong ion outflows from the F region ionosphere during auroral activity: Revisited, J. Geophys. Res., 97(A3), 3019-3037, doi:10.1029/91JA02438.

Wahlund, J.-E., et al. (1993), Electron energisation in the topside auroral ionosphere: The importance of ion-acoustic turbulence, J. Atmos. Terr. Phys., 55, 623-645.

Winser, K. J., et al. (1988), Large field-aligned velocities observed by EISCAT, J. Atmos. Terr. Phys., 50, 379-382.

Winser, K. J., et al. (1989), Observations of large field-aligned flows of thermal plasma in the auroral ionosphere, Adv. Space Res., 9, 57-63.

Yau, A. W., and M. André (1997), Sources of ion outflow in the high latitude ionosphere, Space Sci. Rev., 80, 1-25.

R. Fujii, M. J. Kosch, and S. Nozawa, Solar-Terrestrial Environment Laboratory, Nagoya University, Nagoya 464-8601, Japan. (m.kosch@ lancaster.ac.uk)

Y. Ogawa, National Institute of Polar Research, Tachikawa, Tokyo 190-8518, Japan.

M. T. Rietveld, EISCAT Research Association, Ramfjordmoen, N-9027 Ramfjordbotn, Norway. 